\title{
Antiretroviral therapy with or without protease inhibitors impairs postprandial TAG hydrolysis in HIV-infected men
}

\author{
Lisa J. Ware ${ }^{1}$, Akil G. A. Jackson ${ }^{2}$, Stephen A. Wootton ${ }^{1}$, Graham C. Burdge ${ }^{1}$, John F. Morlese ${ }^{2}$, \\ Graeme J. Moyle ${ }^{2}$, Alan A. Jackson ${ }^{1}$ and Brian G. Gazzard ${ }^{2}$ \\ ${ }^{1}$ Institute of Human Nutrition, Mailpoint 113, Southampton General Hospital, Tremona Road, Southampton SO16 6YD, UK \\ ${ }^{2}$ Chelsea and Westminster Hospital, Fulham Road, London SW10 9NH, UK
}

(Received 21 April 2008 - Revised 15 December 2008 - Accepted 23 March 2009 - First published online 1 June 2009)

Mechanisms underlying the lipodystrophy syndrome associated with antiretroviral therapy (ART) for HIV infection are not completely understood. We investigated the effect of ART on blood lipid concentrations in the fasting state and after consumption of a meal containing $\left[1-{ }^{13} \mathrm{C}\right]$ palmitic acid in HIV-positive men receiving nucleoside reverse transcriptase inhibitors (NRTI, $n$ 7), NRTI combined with protease inhibitors (PI; NRTIPI, $n$ 6), in HIV-positive but therapy-naïve men (noART, $n$ ) ) and in HIV-seronegative men (controls, $n$ 6). HIV-positive subjects had higher fasting TAG concentrations and resting energy expenditure than controls. Subjects receiving NRTIPI therapy had higher fasting NEFA concentrations than the other groups. There were no significant differences in postprandial lipid metabolism between noART subjects and controls. NRTI therapy impaired hydrolysis of meal-derived TAG, most evidently when combined with PI (the NRTIPI group). Accumulation of ${ }^{13} \mathrm{C}$-label in the NEFA fraction was not different between groups. In the NRTIPI group, fasting and postprandial NEFA concentrations were significantly higher than other groups. Postprandial glucose and insulin responses in HIV-positive subjects did not differ from controls. These findings suggest that ART dyslipidaemia is associated with impaired postprandial TAG clearance, which is exacerbated by NRTIPI therapy. If dyslipidaemia is to be minimised in ART, the specific adverse effects of particular combinations during the fed state should be considered.

HIV: Protease inhibitors: Nucleoside reverse transcriptase inhibitors: Dyslipidaemia: Stable isotopes

The mortality and morbidity due to HIV infection and resultant immunosuppression have been significantly reduced by the availability of potent combinations of antiretroviral therapy $(\mathrm{ART})^{(1-3)}$. However, ART can induce metabolic and morphological changes due to perturbations of lipid metabolism ${ }^{(4,5)}$. Specifically, ART is associated with raised fasting TAG and HDL-cholesterol, VLDL TAG and intermediate-density lipoprotein concentration and lower LDLcholesterol concentration ${ }^{(6)}$ leading to increased risk of $\operatorname{CVD}^{(7,8)}$. These changes in lipid metabolism are accompanied by redistribution of fat mass between adipose tissue depots, which because of perceived aesthetic changes may reduce treatment compliance ${ }^{(9,10)}$

The effect of ART in seropositive subjects on the development of hypertriglyceridaemia is well recognised. The effect is variable and has been seen at its most severe extreme in earlier protease inhibitors (PI) therapy. The relative contribution of nucleoside reverse transcriptase inhibitors (NRTI) component within combination therapy is less well understood. Although the magnitude of the effect attributable to NRTI on its own may be smaller, there is increasing concern that when combined with PI, the interaction may result in greater perturbations in lipid metabolism than that seen with PI alone $^{(11)}$. The mechanism underlying ART-associated dyslipidaemia is not well understood, but is reported to involve insulin resistance ${ }^{(12)}$ and increased activity of pro-inflammatory cytokines $^{(13)}$, and in the fasted state, accelerated lipolysis ${ }^{(11,14)}$ and increased VLDL secretion ${ }^{(15)}$. In the fed state, marked perturbations in dietary TAG disposal, seen most obviously as enhanced postprandial lipaemia, are also believed to play an important role in the development of this condition ${ }^{(16)}$. Plasma TAG homeostasis in the fed state reflects the balance between the rates of lipid entering the circulation carried by chylomicron and VLDL, and capacity for clearance of endogenous and meal-derived TAG by lipoprotein lipase activity $^{(17)}$ and the subsequent entrapment of fatty acids released by lipoprotein lipase activity by peripheral tissues ${ }^{(18,19)}$. Incomplete delipidation of lipoproteins and/or entrapment in the postprandial state would increase flux of fatty acids either as TAG in chylomicron remnants or as NEFA to the liver, which in turn drive VLDL TAG secretion. While there is some evidence of impaired clearance of TAG-rich lipoproteins ${ }^{(20,21)}$, the proposal that peripheral fatty acid trapping is impaired is supported only by indirect

Abbreviations: ART, antiretroviral therapy; AUC, area under the curve; NRTI, nucleoside reverse transcriptase inhibitors; NRTIPI, NRTI combined with protease inhibitors; REE, resting energy expenditure.

* Corresponding author: Dr Stephen A. Wootton, fax +44 2380 794945, email saw@southampton.ac.uk 
evidence $^{(21,22)}$. Given that different types or combination regimens of ART lead to varying degrees of dyslipaemia ${ }^{(16)}$, there is a pressing need to determine how the processes leading to dyslipidaemia may be influenced by NRTI-containing regimens with and without PI.

We hypothesised that treatment with NRTI impairs TAG clearance and fatty acid entrapment during postprandial lipaemia and that this effect is exacerbated by combined treatment with NRTI and PI in HIV-positive men with ART dyslipidaemia. We have used stable isotope tracer techniques to measure the postprandial partitioning of dietary lipid following consumption of a mixed meal labelled with $\left[{ }^{13} \mathrm{C}\right]$ palmitic acid in four groups of men: HIV-negative controls; HIV-positive patients not receiving ART; two groups of HIV-positive patients receiving ART with or without PI.

\section{Materials and methods}

\section{Study subjects}

Ethical approval was obtained from the Chelsea \& Westminster Hospital Ethics Committee for all patients and from the Southampton and South West Hampshire Research Ethics Committee for the control subjects. Informed written consent was obtained from all participants. Nineteen asymptomatic HIV-positive men aged 20-54 years were recruited at the Chelsea \& Westminster Hospital, London together with six age-matched HIV-negative healthy male volunteers (controls) from the Institute of Human Nutrition, University of Southampton. The HIV-1-infected subjects were: $n 6$ ART-naïve individuals (noART); $n 6$ individuals receiving PI-based ART (NRTIPI); $n 7$ PI-naïve individuals receiving dual-NRTI regimens ( $n$ 7). Subject characteristics are summarised in Table 1 together with the individual antiretroviral regimens, viral load, CD4 and CD8 count. All patients on ART had self-reported moderate to severe peripheral fat loss and HIV lipodystrophy syndrome was confirmed by clinical examination ${ }^{(10)}$. After completing the metabolic studies, one of the noART patients was found to have a malignancy and was withdrawn from the analysis. Patients in NRTIPI group had been on PI-based regimens for at least 12 months.

\section{Postprandial study}

The subjects avoided foods naturally enriched with ${ }^{13} \mathrm{C}$ (e.g. maize products, cane sugar) for $2 \mathrm{~d}$ before the study and refrained from eating or drinking from 22.00 hours on the day before the study. Participants attended at $07.00 \mathrm{~h}$ and underwent anthropometric assessments and bioelectrical impedance (Bodystat 500 BIA, Bodystat Limited, Isle of Man, UK). REE and substrate oxidation were determined by indirect calorimetry (Deltatrac Metabolic Monitor; Datex Instrumentarium, Helsinki, Finland). Baseline ${ }^{13} \mathrm{C}$-excretion was measured in expired air collected into breath collection bags and transferred to evacuated tubes (Exetainer; Labco Ltd, High Wycombe, UK). Fasting venous bloods were drawn from an indwelling forearm cannula.

Subjects consumed a standard test breakfast providing $3720 \mathrm{~kJ}$ and containing, $45 \mathrm{~g}$ lipid, $93 \mathrm{~g}$ carbohydrate and $33 \mathrm{~g}$ protein. This consisted of cereal, milk, bread, margarine and cheese together with a lipid:glucose:casein emulsion containing $700 \mathrm{mg}\left[1-{ }^{13} \mathrm{C}\right]$ palmitic acid ninety-nine atom per cent excess (Masstrace, Woburn, MA, USA) ${ }^{(23)}$. Venous blood samples were collected at half-hourly intervals for $3 \mathrm{~h}$ and then hourly for the next $4 \mathrm{~h}$. Measurement of gaseous exchange and expired air sampling was performed hourly for $7 \mathrm{~h}$. The patients were only allowed to drink water and were required to remain seated or supine throughout the study period.

\section{Measurement of energy expenditure}

REE and estimates of net lipid and carbohydrate oxidation were made from gaseous exchange measurements ${ }^{(24)}$. Net lipid and carbohydrate oxidation over the $7 \mathrm{~h}$ postprandial period were determined as the area under the curve (AUC) from the time by oxidation plots, and expressed as the relative contribution made by carbohydrate and lipid oxidation towards energy expenditure.

\section{Measurement of fatty acid $\beta$-oxidation}

Enrichment of ${ }^{13} \mathrm{C}$ in breath as ${ }^{13} \mathrm{CO}_{2}$ was determined by continuous-flow-isotope ratio mass spectrometer (20-20 stable isotope analyser, Europa Scientific Ltd, Crewe, UK). The proportion of ${ }^{13} \mathrm{C}$-label excreted on breath as ${ }^{13} \mathrm{CO}_{2}$ was expressed as a percentage of administered ${ }^{13} \mathrm{C}$-label per hour and as the cumulative percentage dose excreted over $7 \mathrm{~h}^{(23)}$. From the whole-body net lipid oxidation and recovery of expired label, it was possible to determine the apparent oxidation of exogenous and endogenous lipid oxidation over the study period. Thus, endogenous lipid oxidation $=$ net lipid oxidation from indirect calorimetry minus exogenous lipid oxidation from ${ }^{13} \mathrm{CO}_{2}$ recovery on breath.

\section{Measurement of total plasma lipids and of ${ }^{13}$ C-labelled fatty acid concentrations in plasma}

Total TAG and NEFA concentrations were measured by summation of the concentrations of individual fatty acids in these pools using GC-combustion-isotope ratio MS (see below). This approach avoided the need to dilute plasma samples with high TAG concentrations, which would have been required if conventional colorimetric analysis had been used. Triheptadecanoin $(100 \mu \mathrm{g})$ and heneicosanoic acid $(30 \mu \mathrm{g})$ were added to plasma $(0.8 \mathrm{ml})$ as internal standards to correct for recovery and tricosanoic acid methyl ester (1.13 atom \%) added to measure isotopic enrichment and total lipids were extracted from plasma with chloroform and methanol ${ }^{(25)}$. TAG and NEFA were purified by solid-phase extraction using $100 \mathrm{mg}$ aminopropylsilica cartridges (Varian, Waltonon-Thames, Surrey, UK) and fatty acid methyl esters were prepared by incubation with $2 \%(\mathrm{v} / \mathrm{v}) \mathrm{H}_{2} \mathrm{SO}_{4}$ in methanol ${ }^{(26)}$. Fatty acid methyl esters were resolved using a HP6890 gas chromatograph (Agilent, Palo Alto, CA, USA) equipped with a BPX-70-fused silica capillary column (SGE, Melbourne, Australia), attached to an Orchid combustion interface (Europa Scientific Ltd, Crewe, UK) and isotopic enrichment was measured by a 20-20 stable isotope analyser (Europa Scientific Ltd). Plasma total TAG and NEFA concentrations were calculated from the GC-C-IRMS chromatograms by dividing the peak area for the fatty acids within the TAG and NEFA fractions by the peak area for the internal 
Table 1. Characteristics of subjects

\begin{tabular}{|c|c|c|c|c|c|c|c|c|c|c|c|c|c|}
\hline & \multicolumn{3}{|c|}{ Control $(n 6)$} & \multicolumn{3}{|c|}{ noART ( $n$ 5) } & \multicolumn{3}{|c|}{ NRTI $(n 7)$} & \multicolumn{3}{|c|}{ NRTIPI $(n 6)$} & \multirow{2}{*}{$\begin{array}{l}\mathrm{K}-\mathrm{W} \\
P<\end{array}$} \\
\hline & Median & Minimum & Maximum & Median & Minimum & Maximum & Median & Minimum & Maximum & Median & Minimum & Maximum & \\
\hline Age (years) & 39 & 32 & 55 & 45 & 20 & 47 & 49 & 31 & 67 & 42 & 35 & 54 & NS \\
\hline Height $(\mathrm{m})$ & 1.78 & 1.71 & $1 \cdot 81$ & 1.81 & 1.65 & 1.87 & 1.72 & 1.68 & 1.78 & 1.77 & 1.68 & 1.80 & NS \\
\hline Weight (kg) & 83.9 & $68 \cdot 3$ & $93 \cdot 1$ & 64.3 & $56 \cdot 6$ & 78.0 & 66.0 & 62.7 & 73.9 & $71 \cdot 1$ & $66 \cdot 3$ & $78 \cdot 1$ & NS \\
\hline $\mathrm{BMI}\left(\mathrm{kg} / \mathrm{m}^{2}\right)$ & $26 \cdot 6$ & 23.4 & 29.4 & 20.8 & $19 \cdot 6$ & $22 \cdot 3$ & $22 \cdot 7$ & $21 \cdot 2$ & 23.1 & 23.8 & 22.4 & $25 \cdot 3$ & NS \\
\hline $\begin{array}{l}\text { Triceps skinfold } \\
\text { thickness }(\mathrm{mm})\end{array}$ & $13 \cdot 6$ & $7 \cdot 1$ & $17 \cdot 9$ & $8 \cdot 0$ & $5 \cdot 1$ & $11 \cdot 4$ & $6 \cdot 6$ & $2 \cdot 4$ & $10 \cdot 4$ & $5 \cdot 7$ & $5 \cdot 1$ & 9.4 & NS \\
\hline Fat mass from BIA (\%) & $17 \cdot 8$ & $15 \cdot 5$ & 22.5 & $17 \cdot 7$ & 13.5 & 24.5 & $16 \cdot 9$ & 6.5 & 22.5 & $14 \cdot 0$ & 11.4 & 19.5 & NS \\
\hline Fat mass from BIA $(\mathrm{kg})$ & $16 \cdot 0$ & 11.4 & $22 \cdot 8$ & 10.5 & $9 \cdot 0$ & 12.5 & $11 \cdot 2$ & 4.2 & $15 \cdot 1$ & $10 \cdot 8$ & $8 \cdot 1$ & $13 \cdot 9$ & NS \\
\hline $\begin{array}{l}\text { Lean body mass } \\
\text { from BIA }(\mathrm{kg})\end{array}$ & $65 \cdot 7$ & 56.9 & $72 \cdot 7$ & $53 \cdot 9$ & $47 \cdot 6$ & $66 \cdot 5$ & 54.8 & $52 \cdot 1$ & $65 \cdot 0$ & $60 \cdot 4$ & $54 \cdot 0$ & $67 \cdot 6$ & NS \\
\hline $\begin{array}{l}\text { Viral load (copies } \\
\quad \times 10^{-3} / \mathrm{ml} \text { plasma) }\end{array}$ & & ND & & $168 \cdot 3^{a}$ & $36 \cdot 8$ & $198 \cdot 7$ & $<0.025^{c}$ & $<0.025$ & $20 \cdot 8$ & $0.4^{\mathrm{b}}$ & 0 & 138.5 & 0.01 \\
\hline $\begin{array}{l}\text { CD4 count (cells } \\
\times 10^{-6} / / \text { plasma) }\end{array}$ & & ND & & $65^{\mathrm{a}}$ & 0 & 362 & $441^{\mathrm{b}}$ & 256 & 939 & $243^{b}$ & 121 & 555 & 0.05 \\
\hline $\begin{array}{l}\text { CD8 count (cells } \\
\times 10^{-6} / / \text { plasma) }\end{array}$ & & ND & & 877 & 96 & 1157 & 994 & 482 & 1544 & 930 & 587 & 2355 & NS \\
\hline Antiretroviral therapy & & NA & & & NA & & & $\begin{array}{l}\text { D4T DDI (3) } \\
\text { AZT DDI (2) } \\
\text { AZT 3TC (1) } \\
\text { D4T (1) }\end{array}$ & & & $\begin{array}{l}\text { D4T DDI RT } \\
\text { D4T 3TC } \\
\text { SQV RTV (2) } \\
\text { D4T 3TC NF } \\
\text { AZT 3TC INL }\end{array}$ & & \\
\hline
\end{tabular}

noART, not receiving antiretroviral therapy; NRTI, nucleoside reverse transcriptase inhibitor; NRTIPI, NRTI with protease inhibitors; K-W, Kruskall-Wallace; BIA, bioelectrical impedance analysis; D4T, stavudine; DDI, didanosine; AZT, zidovudine; 3TC, lamivudine; RTV, ritonavir; IND, indinavir; SQV, saquinavir; NFV, nelfinavir; NVP, nevirapine; ND, not determined; NA, not applicable.

Values are median (minimum and maximum) concentrations of glucose and insulin in plasma from control subjects and from HIV-positive patients who were not receiving noART, or were receiving NRTI or in combination with NRTIPI. Statistical analysis for an effect of group was determined by $\mathrm{K}-\mathrm{W}$ where significance assumed as $P<0.05$

$a, b, c$ Values with different letters are significantly different by the Mann-Whitney $U$ test $(P<0.05)$. 
standards, and multiplying the result to account for the volume of plasma extracted and the amount of internal standard added. Enrichment of ${ }^{13} \mathrm{C}$ in fatty acid methyl esters was expressed quantitatively as micrograms $\left[{ }^{13} \mathrm{C}\right]$ palmitic acid/ml plasma ${ }^{(27)}$.

\section{Metabolic model and data analysis}

The primary changes of interest were the kinetics and time course of $\left[{ }^{13} \mathrm{C}\right]$ palmitic acid in the TAG and NEFA pools within the circulation and the kinetics and time course of ${ }^{13} \mathrm{C}$-label excretion in breath. A summary statement of the TAG and NEFA excursions (both labelled and unlabelled) was derived by determining the AUC. Based on our earlier work $^{(17-19)}$, prolonged retention of $\left[{ }^{13} \mathrm{C}\right]$ palmitic acid as TAG in the circulation was assumed to reflect impaired chylomicron clearance from the circulation by peripheral tissues. Elevation of $\left[{ }^{13} \mathrm{C}\right]$ palmitic acid in the NEFA fraction was assumed to reflect the hydrolysis of chylomicron TAG and impaired entrapment of the resultant fatty acids by peripheral tissues.

\section{Measurement of plasma glucose and insulin concentrations}

Plasma glucose concentration was determined using an automated glucose analyser (AU600, Olympic Diagnostics, Southall, UK). Plasma insulin concentration was measured using an automated ELISA assay (ES700: Roche Diagnostics, Lewes, UK).

\section{Statistical analysis}

Data were entered into a computerised database (SPSS version 10.0; SPSS Inc., Chicago, IL, USA). Given that the number of subjects in each group was relatively small and that much of the data were not normally distributed, the results are presented as median (range). An overall comparison between groups was carried out using Kruskall-Wallace analysis for multiple groups, and where a statistically significant group effect was observed, the Mann-Whitney $U$ test was then used to determine the significance of the difference observed between any two groups. Statistical comparisons between groups of the postprandial response were restricted to comparisons of AUC. Statistical significance was assumed where $P<0 \cdot 05$.

\section{Results}

\section{Subject characteristics}

The groups were of comparable age and although the seropositive men tended to be lighter and exhibit lower BMI, triceps skinfold thickness, fat mass and lean body mass than the controls, these differences did not attain statistical significance (Table 1). Subjects in the noART group had significantly higher viral load and lower CD4 count than the other seropositive groups.

\section{Energy expenditure and substrate oxidation}

Measures of fasting and postprandial energy expenditure with the relative oxidation of macronutrients are shown in Table 2. In the fasting state, when expressed per unit lean body mass, REE was significantly greater in all three seropositive

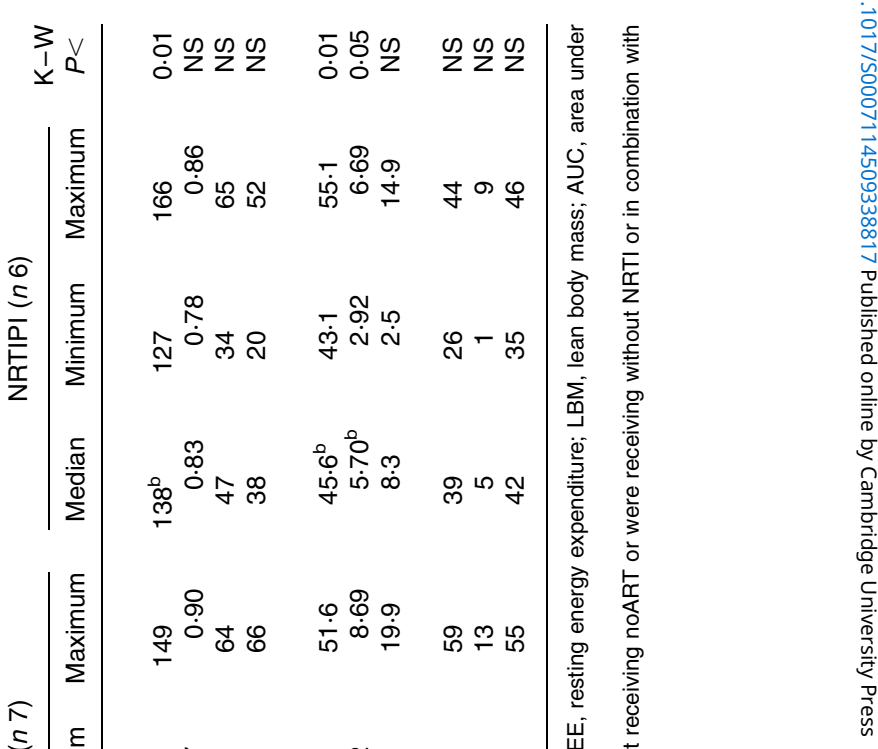

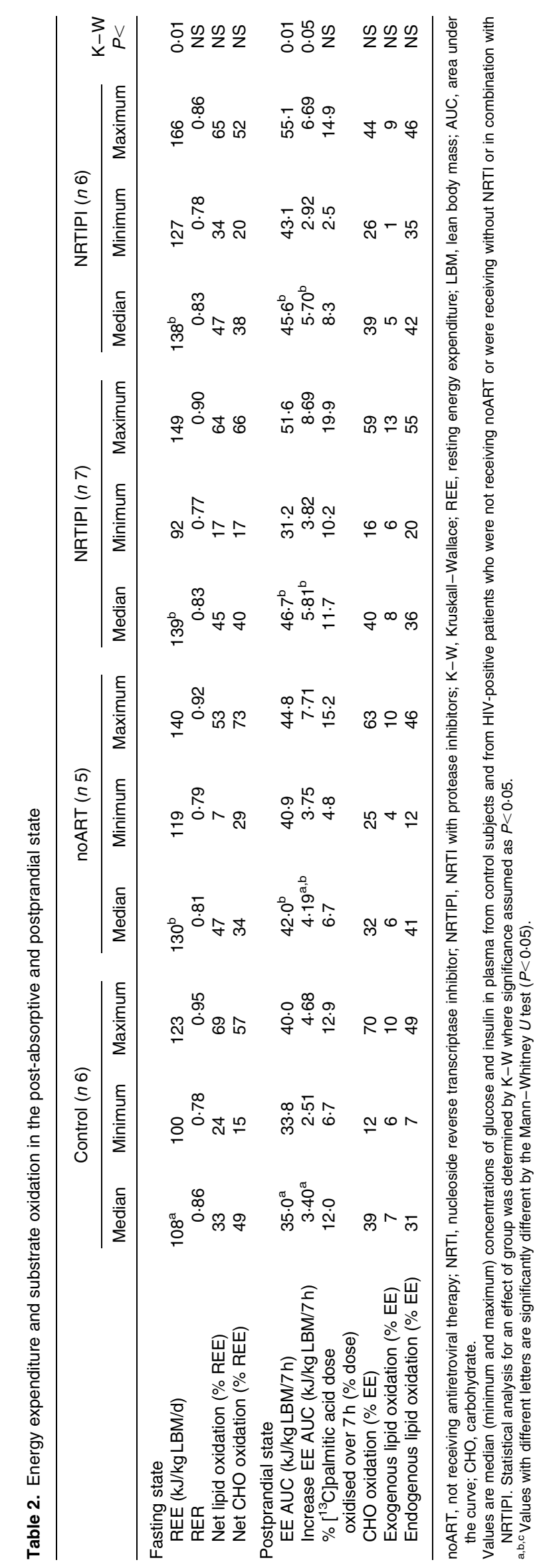


groups relative to controls. There was no significant difference between groups in RER or net substrate oxidation in the fasting state.

In the fed state, energy expenditure expressed per unit lean body mass over $7 \mathrm{~h}$ was approximately $20-33 \%$ greater in the seropositive groups compared with controls, with the greatest increases seen in the NRTI and NRTIPI groups (Table 2). There were no significant differences between groups in either the cumulative recovery of label on breath as ${ }^{13} \mathrm{CO}_{2}$ over $7 \mathrm{~h}$ expressed as a percentage of the administered dose of $\left[1{ }^{13} \mathrm{C}\right]$ palmitic acid or the relative proportions of carbohydrate and lipid (whether expressed as net, endogenous or exogenous lipid) oxidation to energy expenditure over the postprandial period (Table 2).

\section{Postprandial changes in plasma concentration of TAG and} $\left[{ }^{13} C\right] T A G$, glucose and insulin

Fasting TAG was significantly elevated in all three groups of seropositive men than controls with modest elevations seen in noART and NRTI with much greater increases seen in the NRTIPI group (Table 1). Fasting NEFA concentration was raised in the NRTIPI group, but not the other seropositive groups, compared with controls. There were no significant differences between groups in fasting plasma glucose or insulin concentrations (Table 3).

Peak plasma metabolite concentrations in the postprandial state are shown in Table 3 and overall response to the meal is illustrated in Fig. 1 and summarised in Table 4. There was a significant effect $(P<0.05)$ of subject group on peak plasma TAG concentration after the test meal. Peak TAG concentration was $2 \cdot 8$-fold higher in the NRTI group and 11.2-fold higher in the NRTIPI group compared with controls, while the noART group did not differ significantly from controls (Table 3). Peak TAG concentration was 3.9-fold higher in the NRTIPI group than the NRTI group (Table 3). There was a significant effect of group on plasma TAG AUC $(P<0.001)$, on the incremental change in TAG AUC $(P<0.01)$ and on AUC $\left[{ }^{13} \mathrm{C}\right]$ palmitic acid concentration in plasma TAG $(P<0 \cdot 001 ;$ Table 4$)$.

Comparing the noART group with controls, there was no difference in TAG AUC or incremental change in TAG AUC. TAG AUC, but not incremental AUC, was significantly higher in the NRTI (3.1-fold) compared with controls (Table 4). For the NRTIPI subjects, TAG AUC and incremental AUC were significantly higher compared with controls (10.3- and 6.1-fold, respectively) and when compared with the NRTI group (3.3- and 3.6-fold, respectively; Table 4). The rank order for the overall plasma TAG response to the meal was control $\equiv$ noART $<$ NRTI $<$ NRTIPI. The AUC for $\left[{ }^{13} \mathrm{C}\right]$ palmitic acid in TAG did not differ significantly between controls and the noART group, while the NRTI group was 2.5-fold higher and the NRTIPI group 6.7-fold higher than controls (Table 4).

There was a significant effect of subject group on the extent of fall in plasma NEFA concentration after the meal (Table 3 and Fig. 1). The general pattern of fall and subsequent rise in NEFA concentration was similar across groups. Control, noART and NRTI groups started from comparable fasting NEFA levels and exhibited similar degrees of suppression as a percentage of baseline. Subjects in the NRTIPI group

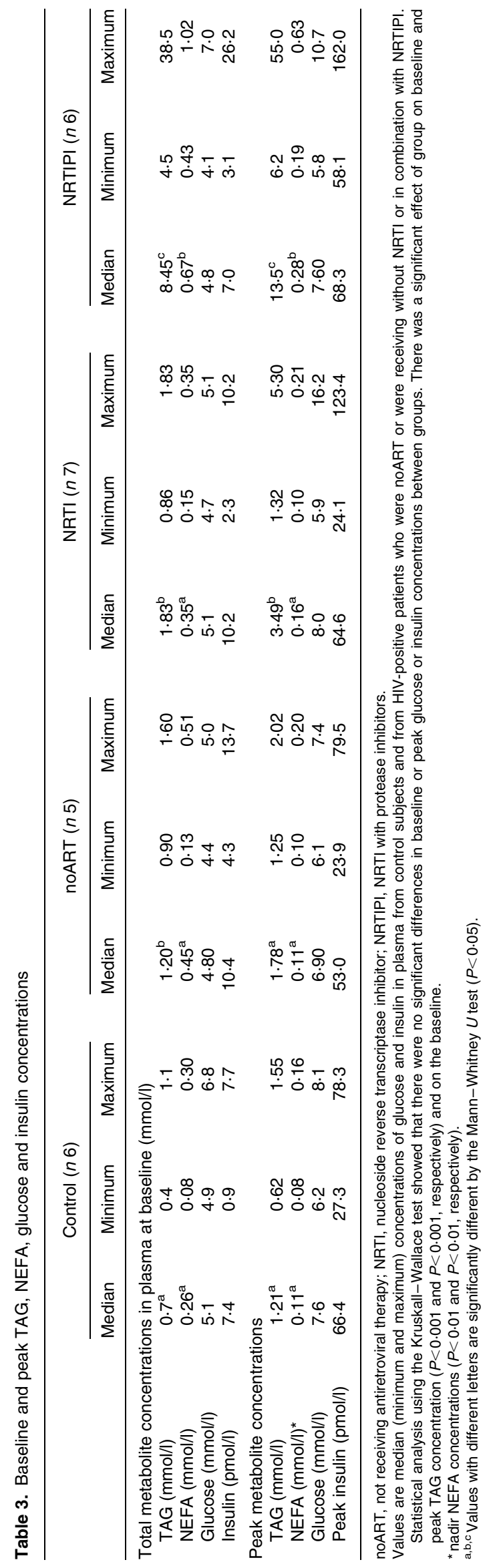



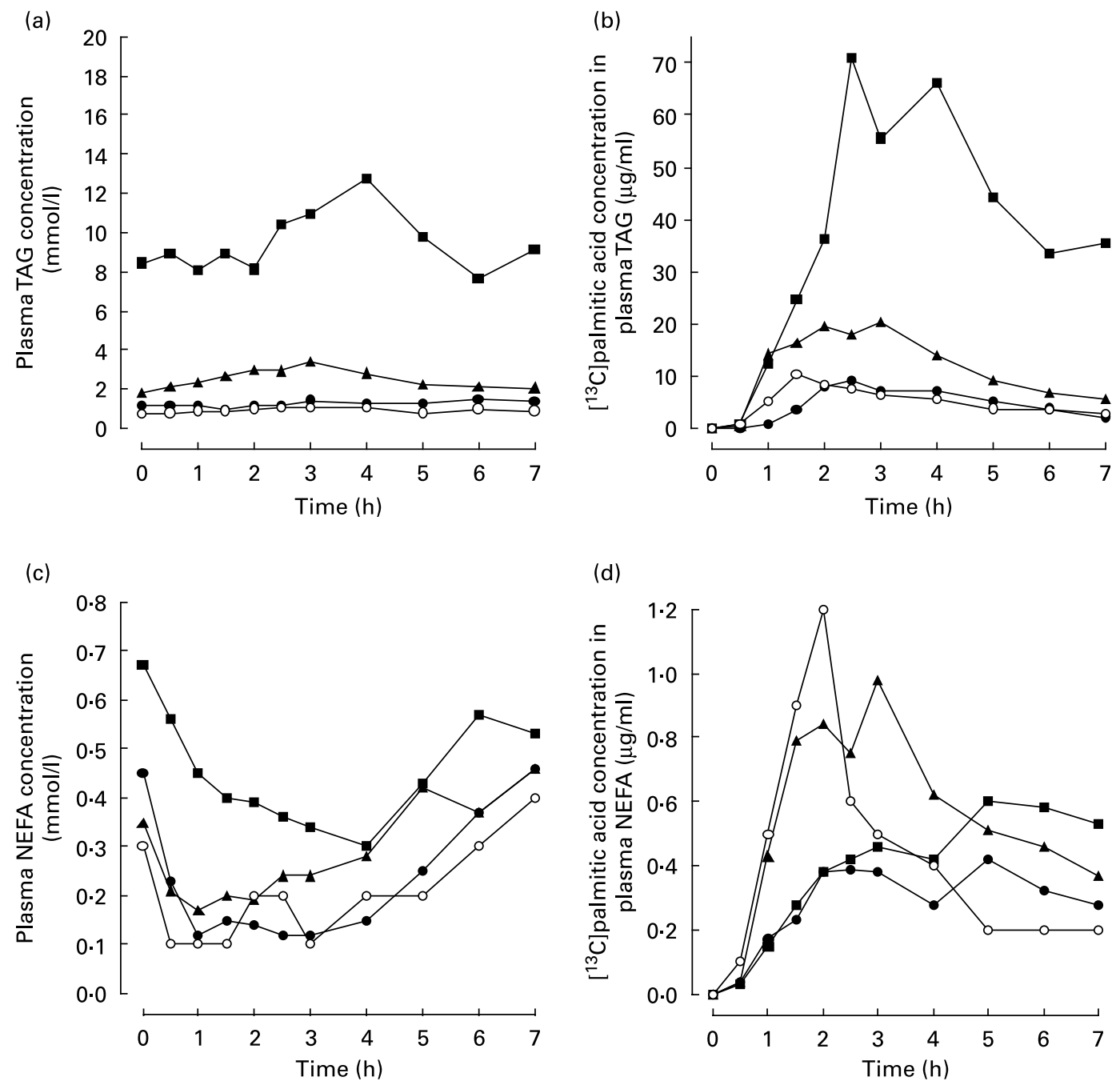

Fig. 1. Changes in plasma total TAG and NEFA concentrations, and in $\left[{ }^{13} \mathrm{C}\right]$ palmitic acid concentration within these pools after consuming the test meal in control (O) subjects and in HIV-positive patients who were not receiving antiretroviral therapy $(\bullet$, noART) or were receiving nucleoside reverse transcriptase inhibitor without $(\Lambda, N R T I)$ or in combination with protease inhibitors ( $\square$, NRTIPI). Changes in individual metabolites are illustrated in plots of median concentrations in (a) plasma total TAG, (b) $\left[{ }^{13} \mathrm{C}\right]$ palmitic acid in plasma TAG, (c) plasma total NEFA and (d) $\left[{ }^{13} \mathrm{C}\right]$ palmitic acid in plasma NEFA.

exhibited a similar proportionate decrease but from a higher fasting baseline. In consequence, postprandial NEFA concentrations were similar to baseline concentrations in the other groups. The rank order for NEFA suppression was control $\equiv$ noART $\equiv$ NRTI $>$ NRTIPI. There was no significant difference between groups in the AUC for $\left[{ }^{13} \mathrm{C}\right]$ palmitic acid concentration in NEFA over $7 \mathrm{~h}$ (Table 4). There were no significant differences in glucose or insulin response between groups (Tables 3 and 4).

\section{Discussion}

Different classes of ART are associated with varying degrees of hypertriglyceridaemia in the fasted state. The results of the present study show that, in the postprandial state, NRTI therapy was associated with a raised and prolonged postprandial lipaemia that was further exacerbated by the addition of PI. These features were not seen in those seropositive men who were not on ART. The increased postprandial lipaemic response was associated with impaired delipidation of TAG-rich lipoproteins derived from lipid within the meal, as marked by the retention of label in the TAG fraction, most strikingly in those on ART containing both NRTI and PI. We were neither able to demonstrate any differences in entrapment of fatty acids released from TAG-rich lipoproteins after the meal as marked by accumulation of tracer in the NEFA fraction, nor was there any evidence of insulin resistance in the seropositive men on ART.

HIV infection per se has previously been associated with demonstrable changes in fasting TAG and NEFA concentration $^{(28)}$ and changes in energy expenditure ${ }^{(29)}$. Previous studies in the fasted state report hepatic greater VLDL secretion in HIV-positive patients receiving PI-containing $\mathrm{ART}^{(30)}$, which may be attributable to increased adipose tissue lipolysis $^{(31)}$ and fatty acid re-esterification ${ }^{(32)}$. We also found increases in fasting TAG and NEFA concentrations and REE, when expressed per unit lean body mass, consistent with chronic infection ${ }^{(33)}$. However, since the NRTIPI group 
had the lowest viral load, but had the highest fasting TAG, NEFA and REE, these findings cannot be attributed to chronic infection alone, but may well reflect more obvious and direct effects of the combining both NRTI and PI within a single ART regimen.

The magnitude of the incremental increase in plasma TAG following the test meal was significantly greater in the NRTI and NRTIPI groups compared with controls and reflected slower clearance of TAG derived from the meal and continuing presence of meal-derived lipid in the circulation. These observations are consistent with the delays in TAG-rich lipoprotein clearance observed in other studies of patients on PI-containing ART regimens ${ }^{(20,21)}$. Moreover, these findings suggest that NRTI treatment alone has a small, but significant, adverse effect on clearance of TAG from the meal, which is exacerbated when combined with PI therapy. There are two possible explanations for these findings, which are not mutually exclusive. Higher fasting TAG and impaired suppression of VLDL TAG secretion in the postprandial state $^{(15)}$ may impair hydrolysis of meal-derived TAG as a result of increased competition between VLDL and chylomicron particles for lipoprotein lipase. Alternatively, lower lipoprotein lipase activity due to a direct effect of ART on synthesis ${ }^{(32,34)}$ or activation of the enzyme may impair TAG clearance. Taken together, both processes would result in slower removal of meal-derived lipid from the circulation. It is not possible to deduce the underlying mechanism from the present data.

It was not possible to directly measure the relative proportions of fatty acids released by the delipidation of chylomicrons that were taken up by the peripheral tissues in the present study, although some indication of the extent of entrapment can be derived from the accumulation of labelled fatty acid in the plasma NEFA pool. In this series, no obvious differences between groups were observed using this approach. It is important to note that the extent to which $\left[{ }^{13} \mathrm{C}\right]$ palmitic acid accumulates in plasma is not solely determined by the degree of entrapment, but would also be influenced by the availability of fatty acids from chylomicron-TAG hydrolysis, the uptake of fatty acids by the liver as well as any reappearance of fatty acids taken up by adipose tissue and then released back into the circulation through lipolysis. For example, marked reductions in the clearance of meal-derived TAG would mean that there would be less $\left[{ }^{13} \mathrm{C}\right]$ palmitic acid available to be taken up by peripheral tissues, and thus marked impairments in entrapment would yield comparable accumulation of $\left[{ }^{13} \mathrm{C}\right]$ palmitic acid in the NEFA pool. Thus, if less fatty acids were derived from TAG hydrolysis in the ART groups, then the same absolute accumulation of $\left[{ }^{13} \mathrm{C}\right]$ palmitic acid accumulation in the NEFA pool may reflect a much lower proportion of these fatty acids being taken up into the tissues (i.e. less entrapment). However, in the absence of modelling direct measures of flux across the tissue beds, we are not able to either confirm or refute the previous indirect reports of a possible effect of ART on fatty acid entrapment ${ }^{(20,22,34)}$.

In contrast to other reports ${ }^{(12,15)}$, the role of insulin resistance in impaired lipid metabolism in these subjects was less clear. Although there were no significant differences between groups, there were trends towards higher insulin and glucose concentrations particularly in the postprandial state. However, 
in the NRTIPI group, the inability to suppress NEFA to the same concentration as seen in other groups would indicate that NEFA levels fail to fall below that usually seen in the fasted state. This may be due to a specific effect of NRTIPI therapy on the regulation of TAG hydrolysis by insulin on adipose tissue, or an effect of the drugs on other enzymes involved in the lipolytic pathway. This observation fits with the suggestion that higher levels of NEFA in the fed state contribute to the maintenance of an insulin-resistant state and serves to drive higher rates of VLDL-TAG synthesis and secretion ${ }^{(35)}$.

It is important to recognise the limitations of these observations, most notably the small sample size and marked between-subject variance, particularly in the ART groups. The clinical phenotypes studied were typical of a patient group with a chronic infective disease receiving multiple therapies and, as such, it is to be expected that there would be heterogeneity among the subjects. We did not set out to impose further exclusion criteria to obtain discreet sub-populations of patients within the defined therapies in order to reduce variability so as to improve the statistical power of the study. To do so would further restrict the observations to a subgroup of the different treatment groups and may incur the criticism that the results were not typical of the overall patient group. It is equally important to recognise that the size of the study groups will always be limited by the size of the pool of potential patients willing to participate in complex, invasive metabolic studies of this kind. The number of subjects studied here is as large if not larger than many of the other published studies in this area of research and typical of metabolic studies in human subjects using stable isotope tracer technologies. Given these constraints, the possibility that the study was insufficiently powered given the heterogeneity to demonstrate differences in fatty acid oxidation or entrapment should not be excluded.

Overall, the present findings suggest that NRTI therapy induces dyslipidaemia at least in part by an impaired clearance of meal-derived TAG. The mechanisms that underlie this change in TAG-rich lipoprotein hydrolysis remain unclear. Equally, there is a need to determine the extent to which hypertriglyceridaemia in ART and other clinical states such as diabetes, metabolic syndrome, obesity and familial hypercholesterolaemia can be attributed to a failure to clear lipid and/or an increased VLDL-TAG secretion arsing from perturbations in adipocyte TAG hydrolysis and increased NEFA flux to the liver or a failure to entrap the products of lipoprotein TAG hydrolysis and/or a failure to suppress VLDL secretion in the fed state. What is clear however is that we need a better understanding of the regulation of lipid metabolism in the fed state and how it might influence cardiometabolic risk. This point is of particular relevance to the treatment of HIV patients as recent evidence from the D.A.D cohort analysis has indicated that specific NRTI were associated with increased mortality from heart disease, which could not be attributed to fasting blood lipids ${ }^{(36)}$. Therapies designed to prevent or minimise dyslipidaemia need to be considered that adverse effects of particular combinations of therapies may have varying metabolic effects in different tissues. From a nutritional perspective, if dyslipidaemia is to be minimised in ART, the specific adverse effects of particular combinations during the fed state should be considered and attention directed towards how such changes in metabolic regulation may be ameliorated or exacerbated by the types of meals consumed within the diet.

\section{Acknowledgements}

The present study was funded by GlaxoSmithKline through the St Stephens AIDS Trust. L. J. W. was in receipt of support from the Geoffrey Taylor Memorial Trust. A. A. J., B. G. G. and S. A. W. designed the study. L. J. W., J. F. M. and G. J. M. carried out the clinical study. L. J. W. carried out the laboratory and statistical analysis. A. G. A. J., S. A. W., G. C. B. and A. A. J. wrote the paper. A. G. A. J., L. J. W., S. A. W., G. C. B., J. F. M., G. J. M., A. A. J. and B. G. G. declare that they have no conflicts of interest. G. C. B. receives salary support from the British Heart Foundation.

\section{References}

1. Egger M, Hirschel B, Francioli P, et al. (1997) Impact of new antiretroviral combination therapies in HIV infected patients in Switzerland: prospective multicentre study. Swiss HIV Cohort Study. BMJ 315, 1194-1199.

2. Palella FJ Jr, Delaney KM, Moorman AC, et al. (1998) Declining morbidity and mortality among patients with advanced human immunodeficiency virus infection. HIV outpatient study investigators. N Engl J Med 338, 853-860.

3. Sendi PP, Bucher HC, Harr T, et al. (1999) Cost effectiveness of highly active antiretroviral therapy in HIV-infected patients. Swiss HIV Cohort Study. Aids 13, 1115-1122.

4. Carr A, Samaras K, Burton S, et al. (1998) A syndrome of peripheral lipodystrophy, hyperlipidaemia and insulin resistance in patients receiving HIV protease inhibitors. AIDS 12, F51-F58.

5. Carr A, Samaras K, Chisholm DJ, et al. (1998) Pathogenesis of HIV-1-protease inhibitor-associated peripheral lipodystrophy, hyperlipidaemia, and insulin resistance. Lancet 351, 1881-1883.

6. Stein JH, Klein MA, Bellehumeur JL, et al. (2001) Use of human immunodeficiency virus-1 protease inhibitors is associated with atherogenic lipoprotein changes and endothelial dysfunction. Circulation 104, 257-262.

7. Iloeje UH, Yuan Y, L'Italien G, et al. (2005) Protease inhibitor exposure and increased risk of cardiovascular disease in HIV-infected patients. HIV Med 6, 37-44.

8. Sudano I, Spieker LE, Noll G, et al. (2006) Cardiovascular disease in HIV infection. Am Heart J 151, 1147-1155.

9. Bernasconi E, Boubaker K, Junghans C, et al. (2002) Abnormalities of body fat distribution in HIV-infected persons treated with antiretroviral drugs: The Swiss HIV Cohort Study. $J$ Acquir Immune Defic Syndr 31, 50-55.

10. Carr A, Emery S, Law M, et al. (2003) An objective case definition of lipodystrophy in HIV-infected adults: a case-control study. Lancet 361, 726-735.

11. Blümer RM, van Vonderen MG, Sutinen J, et al. (2008) Zidovudine/lamivudine contributes to insulin resistance within 3 months of starting combination antiretroviral therapy. AIDS 22, 227-236.

12. Behrens GM, Boerner AR, Weber K, et al. (2002) Impaired glucose phosphorylation and transport in skeletal muscle cause insulin resistance in HIV-1-infected patients with lipodystrophy. J Clin Invest 110, 1319-1327.

13. Fisher SD, Miller TL \& Lipshultz SE (2006) Impact of HIV and highly active antiretroviral therapy on leukocyte adhesion molecules, arterial inflammation, dyslipidemia, and atherosclerosis. Atherosclerosis 185, 1-11. 
14. Hadigan C, Borgonha S, Rabe J, et al. (2002) Increased rates of lipolysis among human immunodeficiency virus-infected men receiving highly active antiretroviral therapy. Metabolism 51, 5 .

15. Reeds DN, Mittendorfer B, Patterson BW, et al. (2003) Alterations in lipid kinetics in men with HIV-dyslipidemia. Am $J$ Physiol Endocrinol Metab 285, E490-E497.

16. Balasubramanyam A, Sekhar RV, Jahoor F, et al. (2004) Pathophysiology of dyslipidemia and increased cardiovascular risk in HIV lipodystrophy: A model of 'systemic steatosis'. Curr Opin Lipidol 15, 59-67.

17. Frayn KN, Coppack SW, Fielding BA, et al. (1995) Coordinated regulation of hormone-sensitive lipase and lipoprotein lipase in human adipose tissue in vivo: implications for the control of fat storage and fat mobilization. Adv Enzyme Regul 35, 163-178.

18. Evans K, Burdge GC, Wootton SA, et al. (2002) Regulation of dietary fatty acid entrapment in subcutaneous adipose tissue and skeletal muscle. Diabetes 51, 2684-2690.

19. Evans K, Burdge GC, Wootton SA, et al. (2007) Tissue-specific stable isotope measurements of postprandial lipid metabolism in familial combined hyperlipidaemia. Atherosclerosis 197, $164-170$

20. Sekhar RV, Jahoor F, Pownall HJ, et al. (2005) Severely dysregulated disposal of postprandial triacylglycerols exacerbates hypertriacylglycerolemia in HIV lipodystrophy syndrome. Am J Clin Nutr 81, 1405-1410.

21. Stein JH, Merwood MA, Bellehumeur JB, et al. (2005) Postprandial lipoprotein changes in patients taking antiretroviral therapy for HIV infection. Arterioscler Thromb Vasc Biol 25, 399-405.

22. van Wijk JP, Cabezas MC, de Koning EJ, et al. (2005) In vivo evidence of impaired peripheral fatty acid trapping in patients with human immunodeficiency virus-associated lipodystrophy. J Clin Endocrinol Metab 90, 3575-3582.

23. Murphy JL, Jones A, Brookes S, et al. (1995) The gastrointestinal handling and metabolism of $\left[1-{ }^{13} \mathrm{C}\right]$ palmitic acid in healthy women. Lipids 30, 291-298.

24. Frayn KN (1983) Calculation of substrate oxidation rates in vivo from gaseous exchange. J Appl Physiol 55, 628-634.

25. Folch J, Lees M \& Sloane Stanley GH (1957) A simple method for the isolation and purification of total lipides from animal tissues. J Biol Chem 226, 497-509.
26. Burdge GC, Wright $\mathrm{P}$, Jones AE, et al. (2000) A method for separation of phosphatidylcholine, triacylglycerol, non-esterified fatty acids and cholesterol esters from plasma by solid-phase extraction. Br J Nutr 84, 781-787.

27. Burdge GC, Jones AE, Frye SM, et al. (2003) Effect of meal sequence on postprandial lipid, glucose and insulin responses in young men. Eur J Clin Nutr 57, 1536-1544.

28. Grunfeld C, Pang M, Doerrler W, et al. (1992) Lipids, lipoproteins, triglyceride clearance, and cytokines in human immunodeficiency virus infection and the acquired immunodeficiency syndrome. J Clin Endocrinol Metab 74, 1045-1052.

29. Macallan DC, Noble C, Baldwin C, et al. (1995) Energy expenditure and wasting in human immunodeficiency virus infection. $N$ Engl J Med 13, 6

30. Sekhar RV, Jahoor F, White AC, et al. (2002) Metabolic basis of HIV-lipodystrophy syndrome. Am J Physiol Endocrinol Metab 283, E332-E337.

31. Kotler DP, Ionescu G, Johnson JA, et al. (2003) Studies of adipose tissue metabolism in human immunodeficiency virus-associated lipodystrophy. Clin Infect Dis 37, Suppl. 2, S47-S51.

32. Baril L, Beucler I, Valantin MA, et al. (2001) Low lipolytic enzyme activity in patients with severe hypertriglyceridemia on highly active antiretroviral therapy. AIDS 15, 415-417.

33. Khovidhunkit W, Kim MS, Memon RA, et al. (2004) Effects of infection and inflammation on lipid and lipoprotein metabolism: mechanisms and consequences to the host. J Lipid Res 45, 1169-1196.

34. den Boer MA, Berbée JF, Reiss P, et al. (2006) Ritonavir impairs lipoprotein lipase-mediated lipolysis and decreases uptake of fatty acids in adipose tissue. Arterioscler Thromb Vasc Biol 26, 124-129.

35. Randle PJ (1998) Regulatory interactions between lipids and carbohydrates: the glucose fatty acid cycle after 35 years. Diabetes Metab Rev 14, 21.

36. D:A:D Study Group, Sabin CA, Worm SW, Weber R, et al. (2008) Use of nucleoside reverse transcriptase inhibitors and risk of myocardial infarction in HIV-infected patients enrolled in the D:A:D study: a multi-cohort collaboration. Lancet 371, 1417-1426, Epub 2008 April 2. Erratum in: Lancet (2008) 372, 292. 